\title{
DIREITOS AUTORAIS COMO INSTITUTO DE PROTEÇÃO DOS CONHECIMENTOS TRADICIONAIS INDÍGENAS
}

\author{
Raquel Rosan Christino Gitahy ${ }^{1}$, Joyce Camargo Fukushima ${ }^{2}$ \\ ${ }^{1}$ Doutora em Educação. Pedagoga. Bacharel em Direito. Docente da Universidade do Oeste Paulista e da Universidade Estadual do \\ Mato Grosso do Sul. ${ }^{2}$ Bacharel em Direito pela Universidade Estadual do Mato Grosso do Sul.
}

\section{RESUMO}

O objetivo do presente artigo foi discutir a participação do índio na formação da identidade cultural da sociedade brasileira, considerando principalmente sua produção cultural e as mudanças na legislação quanto à proteção e consolidação de políticas que assegurem a diversidade social e cultural. Para a realização do objetivo exposto foi efetuada uma pesquisa bibliográfica. A pesquisa focou na verificação da aplicação dos direitos autorais no caso peculiar dos povos indígenas brasileiros a partir de um questionamento sobre as dificuldades enfrentadas pelos juristas para levar esse esclarecimento às comunidades. Um segundo foco foi a discussão a respeito da relevância da aplicação dos direitos autorais como meio de assegurar a identidade cultural indígena, associando: direitos autorais, a importância da proteção aos conhecimentos tradicionais e a relevância do registro do patrimônio imaterial da cultura indígena. Como resultados verificamos que enquanto se aguarda a formulação de uma lei mais completa e específica que leve, em consideração, as principais peculiaridades dos povos indígenas, a população brasileira deve ampliar sua visão social a respeito das as culturas nativas a fim de amenizar as políticas de uniformização e homogeneização da sociedade. Os autores estudados demonstram a ausência no ordenamento jurídico de uma proteção especial ao conhecimento tradicional, fazendo-se necessário que o profissional do direito opte por adaptar a legislação de propriedade intelectual a esses casos.

Palavras-chave: Direitos autorais. Propriedade intelectual. Patrimônio cultural imaterial. Conhecimentos tradicionais. Povos indígenas.

\section{COPYRIGHTS AS INSTITUTE OF PROTECTION OF THE ABORIGINAL TRADITIONAL KNOWLEDGE}

\begin{abstract}
The objective of the present article was to argue the participation of the indian in the formation of the cultural identity of the Brazilian society, considering mainly its cultural production and the changes in the legislation how much to the protection and consolidation of politics that assure the social and cultural diversity. For the accomplishment of the displayed objective a bibliographical research was effected. The research in the verification of the application of the copyrights in the peculiar case of the Brazilian aboriginal peoples from a questioning on the difficulties faced for the jurists to take this clarification to the communities. As a focus was the quarrel regarding the relevance of the application of the copyrights as half to assure the aboriginal cultural identity, associating: copyrights, the importance of the protection to the traditional knowledge and the relevance of the register of the incorporeal patrimony of the aboriginal culture. As results we verify that while the formularization of a more complete law is waited and specific that has led, in consideration, the main peculiarities of the aboriginal peoples, the Brazilian population must extend its social vision regarding the native cultures in order to brighten up the politics of homogenization of the society. The studied authors demonstrate the absence in the legal system of a special protection to the traditional knowledge, becoming necessary that the professional of the right opts to adapting the legislation of copyright to these cases.
\end{abstract}

Keywords: Copyright. Intellectual property. Intangible cultural heritage. Traditional knowledge. Indigenous peoples. 


\section{INTRODUÇÃO}

No último século, o ser humano presenciou momentos de extremo crescimento econômico, desenvolvimento industrial e surgimento de tecnologias extraordinariamente lucrativas. Para tanto, foi necessário ao homem ampliar seu mercado consumidor e, conseqüentemente, novas rotas comerciais e matérias-primas se tornaram essenciais ao acréscimo dos lucros.

Da ampliação do poder de alguns países colonizadores, houve um verdadeiro "saque" nos novos territórios explorados, onde desde recursos naturais até elementos culturais nativos foram violentamente alterados, com a significativa supressão de autonomia dessas populações originárias e desvalorização de sua cultura tradicional.

Assim, a problemática da proteção dos conhecimentos tradicionais se torna matéria focalizada, já que essas nações e futuros países, historicamente colônias de exploração, são os que possuem os maiores exemplos de miscigenação étnica e cultural, com enorme acervo patrimonial cultural.

Decorre daí a importância de discutir e questionar a aplicação dos atuais direitos autorais brasileiros como meio de assegurar as formas de expressão da cultura tradicional indígena, porém ressaltando a possível criação de um instrumento normativo que aborde o assunto de forma mais específica.

Sabendo que a Lei nº. 9.610 de 1998, que trata dos direitos autorais, em seu artigo 11, dispõe que autor é pessoa física criadora de obra literária, artística ou científica, como aplicar tal legislação se em geral a cultura tradicional é traduzida no conhecimento coletivo de determinada comunidade?

A Portaria 177 de 2006, da FUNAI, ao assegurar aos povos indígenas igualdade de condições e justiça de direitos e oportunidades quanto aos demais membros da sociedade, se propôs a interpretar a lei de direitos autorais considerando as necessidades especiais de proteção autoral indígena ainda não regulamentada e estende a proteção autoral também às criações tradicionais.

Entretanto, a proteção de cultura tão nobre não deve ficar restrita à portaria mencionada acima. Nesse sentido, o presente artigo busca a melhor compreensão e a aplicação do direito em esferas ainda pouco conhecidas e expressa, resumidamente, os mecanismos atuais de proteção da cultura brasileira, da propriedade intelectual, do patrimônio imaterial e, conseqüentemente, demonstra os resultados desastrosos do esquecimento dessa identidade cultural tradicional pela qual passam os índios brasileiros.

O Brasil sempre tentou reproduzir a imagem de país tolerante, abrangendo todas as etnias que aqui se estabeleciam. Porém, a história demonstra claramente a primazia da cultura e da visão européia, marcada pelo preconceito perante as culturas nativas, com suas constantes tentativas de supressão étnico-cultural e propostas de integracionismo do Estado brasileiro.

O presente trabalho tem, portanto, o objetivo de apontar e refletir sobre as dificuldades apresentadas em adequar a proteção dos conhecimentos tradicionais indígenas com os instrumentos normativos de proteção intelectual já existente no direito brasileiro.

\section{A importância de salvaguardar o conhecimento tradicional}

Conservar e proteger as criações intelectuais indígenas reflete diretamente no seu modo de vida, pois como já foi dito, sua sobrevivência está ligada à manutenção de seus conhecimentos tradicionais que, por 
conseqüência, fortalece as bases criativas $e$ artísticas desses povos.

Entretanto, somente falar da importância de amparar os conhecimentos indígenas não bastaria. É necessário transcrever os resultados dramáticos adquiridos por tribos que, aos poucos, foram perdendo sua identidade ou que foram brutalmente inseridos em um meio ao qual não estavam acostumados.

Demonstra Oliveira (2007), em sua obra, que os Índios Krahô, habitantes do Tocantins enfrentaram sérios problemas com a perda de biodiversidade agrícola. Graças ao contato com não-índios, deixaram de transmitir suas práticas de plantações tradicionais para seus descendentes, situação agravada por um projeto do governo que fez com que os Krahô plantassem arroz e abandonassem suas roças. Além de sementes e mudas, perderam também muito de seus conhecimentos sobre as plantas, as histórias e cuidados com a terra. Consequentemente, a falta de diversidade na alimentação e o aumento do consumo de alimentos dos não-índios fizeram com que a saúde das pessoas da tribo se deteriorasse.

O mesmo ocorreu com os índios Kaiabi, que vivem no Parque do Xingu, que, pelo contato com os não-índios, acabaram obtendo mudanças bruscas na alimentação. Eles cultivavam 18 tipos de amendoim, atualmente só possuem sete tipos. Os Guaranis, do Estado de São Paulo, também tiveram grandes perdas nas variedades cultivadas e os Guaranis, que habitam o Paraguai, vivem a mesma história por causa das plantações dos não-índios em volta de suas terras, ficando sem terra para plantar.

Oliveira (2007) também cita que os índios Xukuru, moradores do município de Pesqueira, no Estado de Pernambuco, perderam grande parte da floresta para a criação de gado e plantação de soja. Desse modo, perderam os cultivos tradicionais e também poderão perder 0 conhecimento sobre as plantas medicinais, que antes encontravam na floresta, causando um desastre cultural, além do aumento de doenças e da dependência do comércio com os não-índios.

O modo de vida dos índios, abruptamente alterado com o aparecimento do dinheiro nas tribos e da comida industrializada, povos como os habitantes do Xingu passaram a enfrentar doenças como a diabetes e a obesidade. As doenças tradicionais diminuíram, em contrapartida, as doenças dos brancos passaram a se configurar como epidemias, especialmente pelo sedentarismo já que os índios não mais praticam suas atividades normais; muitas vezes se tornam assalariados nas cidades, se tornando grandes consumidores de comida de péssima qualidade

A principal doença do Xingu era a malária, hoje as pessoas sofrem com hipertensão e doenças cardíacas. As crianças sofrem de desnutrição porque sua alimentação base, constituída por peixe e farinha, foi deixada de lado por comidas industrializadas pobres de vitaminas e proteínas.

Oliveira (2006) aponta que as aldeias Xavantes, do Mato Grosso, que ainda consomem a alimentação tradicional como frutos, raízes, milho, abóbora, feijão, peixes e carne da caça possuem baixa incidência de problemas dentários, ao contrário dos que mudaram seu jeito de viver adquirindo o costume de consumir refrigerantes, biscoitos e salgadinhos.

A autora também aponta dados assustadores quando o assunto é relativo ao uso de álcool e drogas pelos indígenas, como o encontrado na Austrália, onde os aborígenes enfrentam sérios problemas, de saúde pública, relacionados ao alcoolismo crônico. Suicídios, cirrose hepática, derrames são as principais causas de mortes e muitos, ainda, se entregam à prostituição e à violência. 
Em concordância com o trabalho "Expressão gráfica e oralidade entre os Wajãpi", do Instituto do Patrimônio Histórico e Artístico Nacional , salvaguardar o conhecimento tradicional também significa evitar que os jovens índios deixem 0 modo de viver de seus antepassados e escolham viver como o homem branco. Entre os Wajãpi, os jovens vêm questionando os saberes dos velhos e muitos acreditam que o conhecimento do não-índio é melhor.

O conhecimento tradicional acolhido como patrimônio cultural imaterial tem sido aprimorado por diversas instituições e muitos países têm se preocupado com instrumentos de proteção da biodiversidade, além de incentivar a diversidade cultural de sua população.

No Brasil a diversidade indígena ainda é pouco conhecida, sobretudo pela rotulação que desgasta a sua imagem. A maioria dos grupos indígenas ainda é discriminada ao tentar o acesso a serviços básicos como saúde e educação.

Se por um lado são esquecidos pelos governantes não-índios, por outro seus conhecimentos se perdem, o que provoca o ocultamento de sua identidade e sua autonomia. Logo, ficam dependentes do assistencialismo do poder público que, como já foi dito, em várias circunstâncias os abandona.

Grande parte dos problemas enfrentados para a legitimação dos direitos sobre o conhecimento tradicional encontra-se na demora da efetivação de políticas públicas, ações afirmativas e de sistemas que ponham em prática essas políticas, assegurando a titularidade desses povos.

A sobrevivência deles depende de ações que defendam os direitos do índio e, também, a conservação do meio ambiente em que, tradicionalmente, vivem, pois seus conhecimentos estão estreitamente relacionados ao cenário que habitam.
Consoante ao artigo "Porque valorizar patrimônios culturais indígenas", de Dominique Gallois (2008), a UNESCO tenta consolidar projetos com a colaboração de organizações não governamentais e organizações que representam as comunidades indígenas para difundirem a importância da conservação cultural. Normalmente, essas ações se baseiam em registros e técnicas, escritas, designando a função de transmissão de informações para os jovens moradores dessas comunidades.

\section{Os Direitos autorais indígenas}

Nas palavras da professora Maria Helena Diniz (2007, p. 178), os direitos autorais indígenas são:

Direitos morais e patrimoniais
sobre as manifestações,
reproduções e criações
estéticas, artísticas, literárias e
científicas; e sobre as
interpretações, grafismos e
fonogramas de caráter coletivo
ou individual indígena, material
ou imaterial indígenas. O autor
da obra, no caso de direito
individual indígena, ou a
coletividade, no caso de direito
coletivo, detêm a titularidade de
sua obra, de protegê-la contra
abusos de terceiros, e de ser
sempre reconhecido como
criador.

O Direito autoral, disposto no artigo $5^{\circ}$, XXVII da Constituição Federal de 1988, lida com a proteção do autor e das obras culturais, científicas e artísticas produzidas, compreendendo formas de remuneração ou sistemas de proteção como copyright, direito do autor ou algum outro que tenha o mesmo objetivo.

Consagrado como um direito fundamental, Bittar (2004, p. 138) traz que:

Em poucas palavras, os direitos autorais sobre uma criação têm nascimento com o advento da obra estética no universo cultural humano. A obra é um 
produto da personalidade humana, e merece proteção desde o instante da criação. Por envolver concepções intelectuais, há que se dizer que, como decorrência disto, parte do que o autor pensa, sente, idealiza, sonha, concebe, distingue, divisa, cunha, vive... é plasmado sobre um corpus mechanicum, de modo que aquele suporte material (fita magnética, papel, tela...), que vem a receber e a agasalhar um lampejo intelectual do criador, deixa de ser simples matéria, para se tornar substância espiritualizada, onde prepondera o arquétipo intelectual do autor como participação espiritual e personalíssima sua sobre 0 mundo.

Para Chaves (1987, p. 107), o direito do autor é:

O conjunto de prerrogativas de ordem não-patrimonial e de ordem pecuniária que a lei reconhece a todo criador de obras literárias, artísticas e cientificas de alguma originalidade, no que diz respeito a sua paternidade e ao seu ulterior aproveitamento, por qualquer meio durante toda a sua vida, e aos seus sucessores, ou pelo prazo que ela fixar.

$\mathrm{Na}$ concepção de Geller (2000), os direitos autorais se desenvolvem seguindo algumas fases. O "pré-copyright" onde se começou a solicitar a participação do Estado para proteger obras de uma possível reprodução não permitida; o "copyright clássico" onde foram aprovadas leis simples reconhecendo direitos dos autores em relação às suas obras, o que dá aos autores 0 poder de fiscalizar o uso não autorizado; por fim o "copyright global", pois diante de um mundo em plena industrialização, com a modernização dos meios de comunicação, há uma grande facilidade em movimentar e espalhar idéias o que acaba por facilitar a difusão das idéias não autorizadas. Assim, o direito autoral surgiu para a sociedade como instrumento garantidor dos lucros comerciais.

Em regra, o direito autoral é um mecanismo para incentivar as produções culturais, cientificas e artísticas, demonstrando os direitos morais e patrimoniais pertencentes aos autores. No sistema jurídico brasileiro, as obras são protegidas desde o momento em que são criadas, sem precisar de nenhum registro anterior.

Pela Lei de Direitos Autorais são obras protegidas as criações do espírito, expressas por qualquer meio ou fixadas em qualquer suporte, tangível ou intangível, conhecido ou que se invente no futuro.

As expressões culturais advindas das tradições populares encontram dificuldades de se enquadrarem na proteção trazida por essa lei, alcançando certa proteção pelo registro do patrimônio imaterial. Porém, o que se percebe é um crescente incentivo para que a produção de bens, relacionada à cultura tradicional, possa ser atingida pela lei de direitos autorais.

A Portaria 177 de 2006 da FUNAI trouxe alguns esclarecimentos sobre os direitos autorais indígenas, observando normas gerais e diretrizes contidas na Constituição Federal, documentos internacionais e na lei dos Direitos Autorais.

Assim, afirmar que os indígenas não têm direito à titularidade dos direitos autorais sobre suas obras apenas demonstra o despreparo das pessoas ao lidar com um tema tão delicado e preocupante.

Gilbert Mariot (2010, n/p), sobre o assunto, afirma:

A Organização Mundial de
Propriedade Intelectual (OMPI)
tratar conhecimentos
tradicionais como um novo
tema a se definir, instituindo o
"Comitê Intergovernamental
sobre Propriedade Intelectual, 
Recursos Genéticos, Conhecimento Tradicional e Folclore", para estudar formas de regulamentar o assunto. Um dos maiores desafios da atualidade, no campo da propriedade intelectual, é proposto pelas populações tradicionais que têm, legitimamente, demandado do Estado, políticas públicas que garantam a proteção de seus conhecimentos tradicionais.

Realmente, todos têm direito de conhecer e utilizar os benefícios do conhecimento indígena, contudo, ninguém tem o direito de modificar, alterar, vender ou passar-se por autor de uma obra que, na verdade, é a arte de um povo que ajudou a fundar o Brasil. Os direitos autorais indígenas têm a finalidade principal de orientar o uso das criações artísticas e outros meios de expressão indígena, protegendo-o de possíveis abusos.

Esses direitos são direcionados a um indivíduo ou à coletividade e são inalienáveis, irrenunciáveis e estão acima de qualquer direito patrimonial. O gozo desses direitos não necessita de autorização da FUNAI e o autor da obra deterá a titularidade sobre o direito autoral, inclusive os direitos patrimoniais referentes ao uso econômico, os quais podem ser cedidos gratuitamente ou mediante remuneração.

As pesquisas que utilizem criações ou obras indígenas devem seguir todos os procedimentos de autorização e procedimentos da Portaria 177, respeitando os costumes e tradições. A comunidade ser previamente informada da cessão do uso desses bens, para que ela tenha consciência sobre a finalidade e o contexto em que serão utilizadas essas informações. Tal portaria reza também:

-A Coordenação Geral de Assuntos Externos da FUNAI analisará os pedidos de autorização de atividades jornalísticas em terras indígenas sempre com a anuência das comunidades indígenas. Além disso, deverá ser assinado um termo de compromisso, respeitando os costumes e tradições do grupo. Não se pode utilizar o material recolhido para uso comercial, observando uma sanção no caso de descumprimento das normas estabelecidas pela FUNAI.

-A Coordenação Geral de Estudos e Pesquisas da FUNAI assistirá nas negociações e revisões de contratos de exploração e uso de imagens, sons, grafismos e demais criações indígenas celebrados com terceiros e emitirá cópias do material produzido para arquivamento na Coordenação Geral de Documentação da Fundação Nacional do Índio.

-As contrapartidas e recursos sobrevindos desses contratos e indenizações serão remetidos aos titulares do direito, mesmo quando se tratar de uma coletividade. Caso não seja possível reverter esses valores diretamente aos titulares, haverá necessidade do depósito ser feito na Renda do Patrimônio Indígena, ou seja, uma conta especial a ser criada pela Coordenação Geral de Patrimônio indígena e Meio ambiente.

-A Coordenação Geral de Índios Isolados analisará casos de autorização de uso e exploração de imagens, sons e criações artísticas de grupos indígenas considerados isolados, ou de pouco contado com o não-indígena.

-A presidência da FUNAI pode suspender, a qualquer tempo, as autorizações concedidas se a comunidade solicitar o cancelamento das atividades, caso as atividades estiverem gerando conflito, afetando o meio ambiente ou causando dano ou ameaça de danos morais ou patrimoniais em terras indígenas e caso haja perigo de contaminação epidêmica.

- As comunidades serão representadas de acordo com seus costumes e tradições, porém, na ausência desse tipo de representação, será admitida a representação feita por pessoas jurídicas. 
Como exemplo de violação de direitos autorais indígenas há a obra "Xingu, Território Tribal", com fotos de Maureen Bisilliat, texto de Orlando Villas Boas e Cláudio Villas Boas, material publicado sem a autorização da comunidade do Xingu. A comercialização das imagens da reserva foi realizada apenas com a permissão expedida pela FUNAI, através da Portaria $n^{\circ}$. 094/76.

Outro caso de violação dos direitos autorais indígenas diz respeito à novela "Aritana", em que a TV Tupi gravou cenas no Parque Nacional do Xingu, inclusive com a participação dos índios em algumas cenas, sem a autorização formal da FUNAI. Diante desse caso, a Terceira Câmara do Conselho Nacional de Direito Autoral aprovou por unanimidade, gerando a Deliberação $n^{\circ} 37$, com a seguinte Ementa:

Direitos Conexos - IndígenasOs direitos devidos pela participação em novela de televisão deverão ser calculados consoante fórmula proposta na presente Deliberação, por inexistência de disposição legal explícita. Os direitos quanto à reparação pela utilização indevida de imagem, deverão ser intentados em Juízo, por ação própria.

A FUNAI permitiu a filmagem em área indígena pela equipe de Produções Cinematográficas L.C. Barreto Ltda, que ingressou na área do Javaé, situado na llha do Bananal, Parque do Araguaia. A equipe se comprometeu em respeitar as diretrizes da FUNAI e, também, os costumes da sociedade Javaé, destinando a essa comunidade o título de direitos autorais e porcentagem pelos rendimentos do filme. Porém, Maria Guiomar Demelo, antropóloga responsável por acompanhar as filmagens, apontou desrespeitos perante os hábitos dos Javaé, e, mesmo com a autorização da FUNAI, para a utilização da imagem dos índios com finalidades comerciais, em nenhum momento houve autorização expressa dos índios.

A respeito da diversidade Biológica, o Brasil ratificou uma Convenção em maio de 1994, instrumento de proteção à biodiversidade, mas que ainda precisa de regulamentação. Tal Convenção consagra a soberania dos Estados sobre os recursos genéticos, implicando no reconhecimento dos direitos intelectuais indígenas sobre a utilização desses recursos quando localizados em áreas indígenas, ou relacionados aos conhecimentos tradicionais.

Não trata da matéria dos direitos indígenas de forma específica apenas sugere normas genéricas, como a repartição dos benefícios arrecadados da utilização de conhecimentos tradicionais, inovações e práticas relevantes à conservação da diversidade biológica. As comunidades devem participar das negociações, exigindo a devida compensação sobre os lucros obtidos de produtos desenvolvidos por meio desses recursos genéticos ou, ainda, da utilização dos saberes tradicionais desses povos.

As formas de compensação não se resumem apenas às compensações pecuniárias, devendo as comunidades ser informadas sobre os resultados da pesquisa, dando a oportunidade dessas pessoas participarem das atividades de pesquisa e essa compensação deve ter natureza coletiva, já que se refere aos conhecimentos de todo um grupo.

Não existe instrumento jurídico internacional que estabeleça princípios ou regras aplicáveis que protejam o folclore ou que o vincule a algum órgão de proteção. A sua proteção deve ser por meio de legislação sui generis, constituindo uma parte do patrimônio imaterial de todo um país.

Ao contrário do que ocorre no conhecimento tradicional, onde se pode distinguir uma determinada comunidade ou indivíduo que 
criou ou manteve viva uma tradição e que, apesar disso, pode também receber proteção por meio do registro de patrimônio imaterial.

No ano de 2002, a Empresa H. Stern Comércio e Indústria S.A. foi condenada, em recurso de apelação, a indenizar uma artista plástica por ter reproduzido e comercializado peças que teriam sido originalmente criadas por ela. Porém, o fato realmente interessante é que se tratava de linha de jóias com temática indígena e, em nenhum momento, foi questionado se essa artista possuía autorização para "copiar" os desenhos, que ela mesma afirmou terem sido desenvolvidos a partir de estudo sobre cestaria, cerâmica, muiraquitãs, máscaras ritualísticas etc.

$\mathrm{Na}$ opinião do desembargador Luiz Augusto Coelho Braga, que votou contra a indenização, não houve a configuração de plágio ou cópia pela empresa, sob a justificativa que a temática indígena constitui patrimônio de domínio público (Apelação Cível no 70001422948, TJ/RS).

Tal equívoco, de apreciar as criações indígenas como propriedade de domínio público, apenas retarda os procedimentos de consolidação dos direitos autorais indígenas. Não resta dúvida que essa idéia deve ser suprimida, principalmente pelos profissionais do direito, que têm o dever de respeitar e aplicar os direitos autorais previstos no ordenamento jurídico a todos brasileiros, sem distinção alguma.

Em seu artigo "Conhecimento tradicional e sistema da proteção da propriedade intelectual", Mariot (2010, n/p) descreve um episódio de nítida violação dos direitos autorais indígenas:

O laboratório Ache, importante empresa do setor bioquímico produziu recentemente um medicamento antiinflamatório chamado "Acheflan", com extrato de erva-baleeira, planta tradicionalmente usada por caiçaras do litoral paulista para tratar contusões e processos inflamatórios. Ocorre que um dos diretores do Laboratório Ache, residente na região litorânea de São Paulo e que costumava jogar futebol com membros da comunidade caiçara daquela região, usava as "garrafadas" para se recuperar das lesões sofridas em decorrência de tais partidas. Segundo consta, este diretor teve a idéia de transformar o conhecimento dos caiçaras em fitomedicamento. Pesquisas ocorreram de 1998 a 2004, para isolar os princípios ativos da erva baleeira e, com aprovação da ANVISA foi feito o depósito do pedido de patente no INPI em 2002. O CGEN (Conselho de Gestão do Patrimônio Genético) viu necessidade de avaliação em razão do acesso a conhecimentos tradicionais. O Laboratório Ache, então, impetrou Mandado de Segurança para garantir o lançamento do produto sem passar pelo CGEN e foi bem sucedido. O produto foi lançado e se transformou em líder de mercado.

Logo, é urgente e imprescindível interpretar extensivamente a proteção da propriedade intelectual aos conhecimentos tradicionais, tendo em vista que o amparo às obras tradicionais é um caso ainda não previsto em lei e que o objetivo principal do direito autoral é a função social de proteção do autor e não somente de arrecadar lucros. O direito autoral indígena deve e tem tudo para se tornar um mecanismo real e aplicável no direito brasileiro.

\section{CONSIDERAÇÕES FINAIS}

O conhecimento tradicional que possui uma autoria determinável, pertencente a um povo ou comunidade, mesmo que concretizado apenas em "idéias" como em lendas e músicas, merecem ser objeto de proteção do direito autoral.

A Lei de Direito Autoral descreve obra coletiva como a criada, organizada e responsabilizada por pessoa física ou jurídica 
constituída por diferentes autores, havendo uma lacuna sobre as obras tradicionais. Assim, deve haver uma interpretação extensiva desses direitos, juntamente com a aplicação da Portaria 177/2006 da FUNAI.

No caso de conhecimento tradicional associado a recursos do patrimônio genético é necessária a existência de um pedido de anuência prévia da comunidade, bem como explicações sobre a finalidade das pesquisas e a possibilidade da participação nos estudos, respeitando o disposto na Convenção da Diversidade Biológica.

Enquanto se aguarda a formulação de uma lei mais completa e específica que leve, em consideração, as principais peculiaridades dos povos indígenas, a população brasileira deve ampliar sua visão social aceitando as culturas nativas e deixar de lado as políticas de uniformização e homogeneização da sociedade.

Enfim, demonstrada a ausência no ordenamento jurídico de uma proteção especial ao conhecimento tradicional, o profissional do direito deve optar por adaptar a legislação de propriedade intelectual a esses casos, verificando a boa-fé dos contratantes e buscando, acima de tudo, a Justiça.

\section{REFERÊNCIAS}

BITTAR, E. C. B. Direitos Autorais Como Direitos Fundamentais da Pessoa Humana. Revista da Faculdade de Direito, São Paulo: USP, 2004.

BRASIL. Portaria da FUNAI número 177 de 16 de fevereiro de 2006. Dispõe sobre os Direitos autorais e de imagem indígenas.

BRASIL. Convenção número 169 da Organização Internacional do Trabalho promulgada pelo Decreto número 5.051 de 19 de abril de 2004. Dispõe sobre os povos indígenas e tribais.

BRASIL. Lei número 9.610 de 19 de fevereiro de 1998. Dispõe sobre direitos autorais. Brasília.
BRASIL. Decreto número 5.051 de 4 de agosto de 2000. Dispõe sobre a identificação, reconhecimento, salvaguarda e promoção da dimensão imaterial do patrimônio cultural. Brasília.

CHAVES, A. Direito de autor. Rio de Janeiro: Forense. 1987.

LADEIRA, M. I. (Coord.) Comunidades Guarani Mbya. Teko Mbaraeterã- Fortalecendo nosso verdadeiro modo de ser. Brasília: CTI (Centro de Trabalho Indigenista). 2005.

DOSSIÊ IPHAN 2. Expressão gráfica e oralidade entre os Wajãpi do Amapá. Rio de Janeiro: Iphan, 2006.

DINIZ, M. H. Curso de Direito Civil Brasileiro: responsabilidade civil. 21.ed. São Paulo: Saraiva, 2007. v. 7.

FRANÇA. Convenção para a salvaguarda do Patrimônio Cultural Imaterial de 17 de outubro de 2003. Paris.

GALLOIS, D. T. Por que valorizar patrimônios culturais indígenas? Ciência e cultura, São Paulo, v. 60, n. 4, 2008.

GELLER, P. E. "Copyright history and the future: What's culture got to do with it?". Journal of the Copyright Society of the USA, $v$. 47, 2000.

INBRAPI. Carta da Kari - Oca. Disponível em: <http://www.inbrapi.org.br/artigo.php?id=11>. Acesso em 4 de Nov. 2009.

INSTITUTO SOCIOAMBIENTAL. Arte Ticuna. Disponível em:

$<$ http://pib.socioambiental.org/pt/povo/ticuna/1349 >. Acessado em 22 de ago. 2010.

MARIOT, G. Conhecimento Tradicional e sistema da proteção da propriedade intelectual. Disponível em:

<http://www.tecnologiasa.com.br/2010/07/23/conh ecimento-tradicional-e-sistema-da-protecao-dapropriedade-intelectual>. Acesso em 21 de agos. 2010.

\section{MUNDURUKU, D. Entrevista - Daniel}

Munduruku. Disponível em:

$<$ http://www.consciencia.net/entrevista-danielmunduruku/ >. Acesso em 11 de ago. 2010.

OLIVEIRA, J. C. Alguns conhecimentos sobre agricultura. São Paulo: lepé, 2007.

OLIVEIRA, J. C. Alguns conhecimentos sobre alimentação. São Paulo: lepé. 2006. 
RELATÓRIO Mundial da UNESCO. Investir na diversidade cultural e no diálogo intercultural. Disponível em:

<http://unesdoc.unesco.org/images/0018/001847/ 184755por.pdf>. Acesso em 13 de ago. 2010.

REVISTADASONGS. Comissão Pro-Índio (CPI/AC). Disponível em:

$<$ http://www.revistadasongs.com.br/projetos.php? ed $=17 \&$ regiao $=1>$. Acessado em 22 de ago.

2010. 